\title{
Antibacterial, Antibiofilm and Anti-adhesion Activities of Piper Betle Leaf Extract Against Avian Pathogenic Escherichia Coli
}

\author{
Pawinee Kulnanan \\ Walailak University \\ Julalak Chuprom \\ Walailak University \\ Thotsapol Thomrongsuwannakij \\ Walailak University \\ Chonticha Romyasamit \\ Walailak University \\ Suthinee Sangkanu \\ Walailak University \\ Nannaphat Manin \\ Prince of Songkla University - Hat Yai Campus: Prince of Songkla University \\ Veeranoot Nissapatorn \\ Walailak University \\ Maria de Lourdes Pereira \\ University of Aveiro: Universidade de Aveiro \\ Polrat Wilairatana \\ Mahidol University \\ Watcharapong Mitsuwan ( $\nabla$ 1234_k@hotmail.co.th ) \\ Walailak University https://orcid.org/0000-0002-5257-4626
}

\section{Research Article}

Keywords: Piper betle, Avian pathogenic Escherichia coli, biofilm formation, established biofilm, and adhesion

Posted Date: June 18th, 2021

DOI: https://doi.org/10.21203/rs.3.rs-620785/v1

License: (c) (1) This work is licensed under a Creative Commons Attribution 4.0 International License. Read Full License 
Version of Record: A version of this preprint was published at Archives of Microbiology on December 21st, 2021. See the published version at https://doi.org/10.1007/s00203-021-02701-z. 


\section{Abstract}

Piper bet/e leaves have traditionally been used to treat many diseases, including bacterial infections. The present study aimed to investigate the antibacterial, antibiofilm, and anti-adhesion activities of $P$. betle extract against Avian pathogenic Escherichia coli (APEC). The ethanol extract of $P$. betle leaves demonstrated strong antibacterial activity against clinical isolates of APEC with MIC and MBC values ranging from $0.5-1.0 \mathrm{mg} / \mathrm{mL}$. Disruption and breakdown of the bacterial cells were detected when the cells were challenged with the extract at $2 \times \mathrm{MIC}$. Bacterial cells treated with the extract demonstrated longer cells without a septum, compared to the control. The extract at $1 / 8,1 / 4$, and $1 / 2 \times \mathrm{MIC}$ significantly inhibited the formation of bacterial biofilm of the isolates $(P<0.05)$ without inhibiting growth. At $1 / 2 \times$ MIC, $55 \%$ of the biofilm inhibition was detected in APEC CH09, a strong biofilm producer. At $32 \times \mathrm{MIC}, 88 \%$ of the inhibition of viable cells embedded in the mature biofilm was detected in APEC CH09. Reduction in the bacterial adhesion to surfaces was shown when APEC were treated with sub-MICs of the extract as observed by SEM. The results suggested potential medicinal benefits of $P$. betle extract for the treatment of the infection caused by Avian pathogenic E. coli.

\section{Introduction}

Escherichia coli (E. coli) is a Gram-negative commensal bacterium that can be found in the intestinal tract in humans and various species of animals. Although most strains are harmless, some strains can cause fatal diseases (Mare et al. 2021). In addition, the bacterium is a versatile microorganism that contains many pathotypes that cause a variety of diseases. The pathogen is the cause of enteric diseases, such as diarrhea or dysentery (Gomes et al. 2016), referred to diarrheagenic E. coli (DEC) strains. Conversely, extra-intestinal pathogenic E. coli (ExPEC) represents an emerging pandemic strains that plays roles in infections outside the intestinal tract, such as the urinary tract infections (UTIs), bacteremia, and meningitis (Cunha et al. 2017). ExPEC pathotypes are classified into uropathogenic E. coli (UPEC), septicemia-associated E. coli (SEPEC), neonatal meningitis causing E. coli (NMEC), and Avian pathogenic E. coli (APEC) that lead to UTIs, septicemia, neonatal meningitis, and colibacillosis in poultry, respectively (Meena et al. 2021). Avian pathogenic E. coli (APEC) is an important pathogen that causes economic losses in poultry production worldwide. Several studies have reported that APEC is highly similar to UPEC and NMEC in humans (Cunha et al. 2017; Jørgensen et al. 2019; Zhuge et al. 2021). Moreover, APEC was considered zoonotic and serves as an external source for human extra-intestinal infections (Kathayat et al. 2021; Stromberg et al. 2017). Hence, poultry can act as a cause of APEC infections in humans. Furthermore, APEC becomes an important pathogen for the poultry industry and public health worldwide.

APEC has a broad selection of virulence factors that promote adhesion and biofilm formation in pathogenesis. Adhesion is the first step in the progress of bacterial infection, followed by colonization to host cells (Ali et al. 2020). The process occurs in matrices that resemble bacteria attached to the pedestal, enabling the formation of biofilms (Rodrigues et al. 2019). Biofilm formation is one of the hallmark strategies used by bacteria to survive in harsh environments (Gu et al. 2019). Due to the development of biofilms, APEC becomes aggregated and difficult to eradicate (Sharma et al. 2016).This 
mechanism enables pathogenic bacteria to tolerate higher concentrations of antibiotics, leading to chronic infection and the emergence of antibiotic-resistant strains (Gu et al. 2019; Hall et al. 2017; Khairy et al. 2020). Furthermore, the treatment of APEC infections is becoming difficult due to the increasing antibiotic resistance of the pathogenic strains (Duan et al. 2020; Saha et al. 2020).

In order to overcome the infection caused by antibiotic resistant APEC, alternative therapeutics based on natural products have been investigated. In literature, medicinal plants have been reported for antimicrobial activity against E. coli, such as seeds of Annona senegalensis (Tamfu et al. 2020), or Rosmarinus officinalis (Lagha et al. 2019). The present study focused on Piper betle (P. bet/e), known as a betel vine. The plant species belongs to the Piperaceae family, a plant native to South and Southeast Asia. Leaves of this plant species have been used in herbal medicine to treat several infectious diseases (Pecková et al. 2018). P. betle has antioxidant, antibacterial, and antifungal activities due to its phytochemicals and essential oil (Salehi et al. 2019). Furthermore, the antibacterial activity of the ethanol extract of $P$. betle leaf against $E$. coli has been reported as a bactericidal agent (Nayaka et al. 2021).

To the best of our knowledge, no study on this local plant against Avian pathogenic E. coli has been scientifically reported. Therefore, the aims of this study were to investigate the antimicrobial activity and the antibiofilm formation ability of Piper betle leaf against Avian pathogenic E. coli. The antibacterial activity was investigated using disc diffusion assay, broth microdilution assay, and time kill kinetic study. Subsequently, the effects of the extract on the biofilm formation, established biofilm, and adhesion of pathogens were determined. Finally, the morphology of APEC treated with the extract was observed by scanning electron microscope.

\section{Materials And Methods}

\subsection{Bacterial strains and growth condition}

Ten clinical isolates of Avian pathogenic Escherichia coli CH01-10 isolated from chicken were used and classified as APEC by our research team (Ethical approval with Ref. No. WU-AEC-016-62) as described (Thomrongsuwannakij et al. 2020). E. coli ATCC 25922 was used as a reference strain. The bacteria were grown on Tryptic Soy Agar (TSA) (Difco, Claix, France) and incubated at $37^{\circ} \mathrm{C}$ for $24 \mathrm{~h}$. The pathogens were then inoculated in Tryptic Soy Broth (TSB) (Himedia, Nashik, India) at $37^{\circ} \mathrm{C}$ for $18-24 \mathrm{~h}$, stored in TSB containing $25 \%$ glycerol at $-80^{\circ} \mathrm{C}$ until use.

\subsection{Preparation of plant extracts}

Fifty grams of dry powder of $P$. betle leaves were extracted in $200 \mathrm{~mL}$ of $95 \%$ ethanol for 7 days at room temperature. The sample was filtered and then evaporated under reduced pressure. The extract was airdried at room temperature. The extract was dissolved in 100\% dimethyl sulfoxide (DMSO) and stored at $4^{\circ} \mathrm{C}$.

\subsection{Disc diffusion assay}


The disc diffusion method was used to screen the antibacterial activity of $P$. bet/e extract against clinical isolates of APEC as previously described (Jaber et al. 2021). Briefly, $12.5 \mu \mathrm{L}(200 \mathrm{mg} / \mathrm{mL})$ of plant extract was applied to sterile filter paper discs ( $6 \mathrm{~mm}$ diameter) to give a final concentration of $2.5 \mathrm{mg} / \mathrm{disc}$. Cultures of the bacteria were adjusted to the McFarland No. 0.5 standard and spread on Mueller-Hinton agar (MHA) (Difco, Claix, France) plates. The discs were placed onto the bacterial cultured plates and incubated at $37^{\circ} \mathrm{C}$ for $18 \mathrm{~h}$. Ampicillin (Oxoid, Hampshire, UK) and gentamicin (Oxoid, Hampshire, UK) were used as positive controls. Meanwhile, a disc loaded with $1 \%$ DMSO was used as a negative control. The antibacterial activity was evaluated by measuring the diameter of the inhibition zones $(\mathrm{mm})$. The experiment was performed in triplicate. The data was presented as mean \pm SD.

\subsection{Determination of Minimal inhibitory concentration (MIC) and Minimal bactericidal concentration (MBC)}

The antibacterial activity of the extract against the clinical isolates was determined using the broth microdilution method according to the Clinical and Laboratory Standards Institute (CLSI, 2007. Briefly, the $P$. betle extract was diluted in a 96-well microtitre plate to the final concentration ranging from 2.0-0.125 $\mathrm{mg} / \mathrm{mL}$ in Mueller-Hinton broth (MHB) (Difco, Claix, France). The bacterial suspension (100 $\mu \mathrm{L}, 10^{6}$ $\mathrm{CFU} / \mathrm{mL}$ ) was inoculated to each well and incubated at $37^{\circ} \mathrm{C}$ for $18 \mathrm{~h}$. Then, $0.03 \%$ of resazurin (Thermo Fisher Scientific, Lancashire, UK) was used to determine the MIC values. The MIC was defined as the lowest concentration that completely inhibited the bacterial growth that present a blue color (Pereira et al. 2021). The MBC was performed with the extract that gave significant MIC values, by streaking the culture on TSA plates. Experiments were assessed in triplicate.

\subsection{Time-kill study}

Time-kill kinetic study of the extract against a representative strain of Avian pathogenic E. coli $\mathrm{CH} 9$ was investigated. An inoculum $\left(10^{6} \mathrm{CFU} / \mathrm{mL}\right)$ of the bacterial cultures was grown in the tested medium supplemented with the plant extract at 1,2 , and 4 times of $\mathrm{MIC}$ and incubated at $37^{\circ} \mathrm{C}$. A final concentration of DMSO presented in the extract was $1 \%$. Hence, one percent DMSO was used as a negative control. Samples were collected at $0,2,4,6,8,12,18$, and $24 \mathrm{~h}$. At each time point, $100 \mu \mathrm{L}$ of the sample were serially diluted in sterile phosphate buffered saline (PBS). Viable counts were determined by a drop plate method in TSA. The plates were incubated at $37^{\circ} \mathrm{C}$ for $24 \mathrm{~h}$. The experiment was carried out in triplicate and the results were presented as mean log numbers of organisms \pm standard deviation.

\subsection{Biofilm forming ability of Avian pathogenic E. coli}

The biofilm forming ability of the isolates of Avian pathogenic E. coli was determined by crystal violet assay. All strains of E. coli, including the reference strain, were grown in TSB supplemented with $1 \%$ glucose and incubated at $37^{\circ} \mathrm{C}$ for $18-24 \mathrm{~h}$. An inoculum $\left(10^{6} \mathrm{CFU} / \mathrm{mL}\right)$ of the cultures was then grown in the tested medium in $96-$ well plates and incubated at $37^{\circ} \mathrm{C}$ for $24 \mathrm{~h}$. The wells containing biofilm were gently washed with PBS and air dried. The biofilm was stained with $0.1 \%(\mathrm{w} / \mathrm{v})$ crystal violet solution $(200 \mu \mathrm{L})$ for $30 \mathrm{~min}$. Wells were rinsed three times with distilled water to remove excess dye. The biofilms 
were dissolved in ethanol and measured at an optical density (OD) $500 \mathrm{~nm}$. The biofilm produced by the pathogen was evaluated as described (Gajewska et al. 2020),

$\mathrm{OD}$ isolate $\leq \mathrm{OD}$ control $=$ Non biofilm forming ability

$O D$ control $<O D$ isolate $\leq 2 O D$ control $=$ Weak biofilm forming ability

OD control $<$ OD isolate $\leq 4 O D$ control = Moderate biofilm forming ability

4OD control $\leq$ OD isolate $=$ Strong biofilm forming ability

\subsection{Effects of $P$. betle extract on biofilm formation of Avian pathogenic E. coli}

The effects of $P$. betle extract on biofilm formation of Avian pathogenic $E$. coli were investigated using the crystal violet assay as described (Mitsuwan et al. 2020). Briefly, an inoculum $\left(1 \times 10^{6} \mathrm{CFU} / \mathrm{mL}\right)$ of the overnight cultures of the bacteria was then grown in the medium tested in 96-well plates supplemented with $P$. betle extract at $1 / 2,1 / 4$, and $1 / 8 \times$ MIC. One percent DMSO was used as a negative control. The plates were incubated at $37^{\circ} \mathrm{C}$ for $24 \mathrm{~h}$. The activity of the extract in the biofilm formation was investigated by crystal violet assay as described above. The inhibitory activity was investigated by the quantification of biofilm formation at the optical density of $570 \mathrm{~nm}$. The relative percentage of biofilm formation was defined as: (mean A570 of treated well/mean A570 of control well) $\times 100$.

\subsection{Effects of $P$. betle extract on established biofilm of Avian pathogenic E. coli}

The effects of Piper betle extract on the established biofilm of Avian pathogenic E. coli were assessed in 96-well plates, as described (Mitsuwan et al. 2020) with modification. Briefly, the overnight culture of $E$. coli $\left(1 \times 10^{6} \mathrm{CFU} / \mathrm{mL}\right)$ was added to 96 -well microtiter plate and incubated at $37^{\circ} \mathrm{C}$ for 2 days to develop young established biofilm and 5 days to develop mature established biofilm. Each well was replaced with new medium every 2 days. Then, the extract in concentrations of 8-32 times of MIC was added to eradicate the established biofilms, incubated at $37^{\circ} \mathrm{C}$ for $24 \mathrm{~h}$. The final concentration of DMSO was $1 \%$, and this concentration of DMSO was used as a negative control. To assess the effect of the extract on established biofilms, the medium was removed and $200 \mu \mathrm{L}$ of PBS with $10 \mu \mathrm{L}$ of 3-(4, 5-dimethylthiazol-2yl)-2, 5-diphenyltetrazolium bromide, MTT, $5 \mathrm{mg} / \mathrm{ml}$; Invitrogen, Oregon, USA) were replaced, incubated at $37^{\circ} \mathrm{C}$ for $2 \mathrm{~h}$. The MTT assay was used to determine the living bacterial cells. Formazan, the purple insoluble crystals, were dissolved by adding DMSO into each well. Then, the samples were measured at $570 \mathrm{~nm}$ by a microplate reader to determine the relative percentage of viability of the biofilm. The relative percentage of the viability was defined as: (mean A570 of treated well/mean A570 of control well) $\times 100$.

\subsection{Effects of $P$. betle extract on adhesion of Avian pathogenic E. coli}


The effects of $P$. betle extract on adhesion of APEC were observed by scanning electron microscope (SEM), as described (Mitsuwan et al. 2020) with modification. Briefly, the bacterial cells were cultured in

TSB supplemented with $1 \%$ glucose, incubated at $37^{\circ} \mathrm{C}$ for $18 \mathrm{~h}$. The bacterial cells $\left(1 \times 10^{6} \mathrm{CFU} / \mathrm{mL}\right)$ were then attached to a sterile glass coverslip $(0.5 \mathrm{~cm} \times 0.5 \mathrm{~cm})$ in a 24-well plate containing the extract in concentrations $1 / 2$ and $1 / 4 \times$ MIC. One percent DMSO was used as a negative control. The samples were incubated at $37^{\circ} \mathrm{C}$ for $24 \mathrm{~h}$. Then, the samples were rinsed twice with PBS. Subsequently, glutaraldehyde fixation (2.5\% in PBS) was carried out for $2 \mathrm{~h}$. The samples were washed with PBS and dehydrated in a series of graded ethanol (20-100\%). The discs were dried in a critical point dryer and coated with gold particles. The adhesion of the bacteria was observed under SEM (Zeiss, Munich, Germany).

\subsection{Morphology of Avian pathogenic E. coli after treatment with $P$. betle}

The effects of $P$. betle extract on morphology of the APEC were investigated by SEM as previously reported (Mitsuwan et al. 2020) with some modification. Briefly, the bacterial cells were cultured in MHB, incubated at $37^{\circ} \mathrm{C}$ for $18 \mathrm{~h}$. The bacterial cells $\left(1 \times 10^{6} \mathrm{CFU} / \mathrm{mL}\right)$ were then grown in a centrifuge tube containing the extract at 4 and $8 \times \mathrm{MIC}$, incubated at $37^{\circ} \mathrm{C}$ for $24 \mathrm{~h}$. The final concentration of DMSO was $1 \%$, and this concentration of DMSO was used as a negative control. The samples were then centrifuged at 5,000 rpm for 5 minutes. The bacterial pellet was dropped on a sterile glass coverslip $(0.5 \mathrm{~cm} \times 0.5 \mathrm{~cm})$, and air dried. Specimens were fixed in glutaraldehyde, dehydrated in ethanol, and preparation of the samples for SEM were carried out as described above. Morphology of the bacteria after treatment with the extract was observed by SEM.

\subsection{Statistical analysis}

The experiments were performed in triplicate. The results were recorded and entered using the statistical package version 19 (SPSS Inc.Chicago, IL, USA). The results were expressed as mean \pm SD. The two-tailed unpaired Student's t-test was used to analyze the statistical analysis. It was reported that $P<0.05$ was considered statistically significant difference.

\section{Results}

\subsection{Preliminary screening of antibacterial activity of $P$. bet/e extract against Avian pathogenic E. coli}

The preliminary screening of antimicrobial activity of the extract against the isolates was investigated at a concentration of $2.5 \mathrm{mg} / \mathrm{disc}$. P. betle extract had antibacterial activity against clinical isolates of APEC (Table 1). The inhibition zone of the extract against the clinical isolates ranged from $18.67 \pm 1.53$ to $21.33 \pm 0.58 \mathrm{~mm}$. The inhibition zone of the extract against the reference strain was in the same range as 


\subsection{Minimal inhibitory concentration (MIC) and minimal bactericidal concentration (MBC) of $P$. betle against Avian pathogenic E. coli}

The antibacterial activity of $P$. betle extract against ten clinical isolates of Avian pathogenic E. coli was determined by a broth microdilution assay. The $P$. betle extract showed strong antibacterial activity against the clinical isolates with the MIC values ranging from $0.5-1.0 \mathrm{mg} / \mathrm{mL}$ (Table 2). In addition, the $M B C$ value of the extract against the isolates was $1.0 \mathrm{mg} / \mathrm{mL}$. It was found that the MIC and MBC values of $P$. betle extract against $E$. coli ATCC 25922 were in the same range as those of the tested clinical isolates.

\subsection{Time kill study}

The time kill curve was determined to confirm the antibacterial effectiveness of $P$. betle extract against Avian pathogenic E. coli. A clinical isolate $\mathrm{CH} 09$ was used as a representative due to its strong biofilm forming ability. The results demonstrated that the antibacterial activity of $P$. betle extract was dependent on the concentration, resulting in the reduction of the colony-forming unit of the pathogen (Fig. 1). Interestingly, the killing activity of the extract at $4 \times \mathrm{MIC}$ against the pathogen was observed within $4 \mathrm{~h}(3$ log inhibition). Furthermore, the viability of the bacteria after treatment with the extract at $2 \times \mathrm{MIC}$ decreased by 3 logs in $12 \mathrm{~h}$. The extract at $1 \times$ MIC exhibited bacteriostatic effects against bacteria in $8 \mathrm{~h}$. However, regrowth was observed in the clinical isolate treated with the extract at $1 \times$ MIC.

\subsection{Morphylogy of Avian pathogenic E. coli after treatment with $P$. betle extract}

The morphology of APEC cells treated with $P$. betle extract was observed by SEM. Rod shape and smooth surface of the bacterial cells were observed in the control groups of the isolate (Fig. 2A-2C) and the reference strain (Fig. 2J-2L). It was found that both of the isolate (Fig. 2D-2I) and the reference strain (Fig. $2 \mathrm{M}-2 \mathrm{R}$ ) treated with the extract showed an abnormal shape when compared to the control. Long cell formation and dried shape of the cells were observed when the pathogens were treated with the extract in $2 \times \mathrm{MIC}$ and $4 \times \mathrm{MIC}$. Furthermore, disruption and breakdown of the bacterial cells were detected when the cells were challenged with the extract. It was noted that the bacterial cells treated with the extract demonstrated longer cells without septum when compared to the control. However, the normal size of the cells was observed.

\section{5. $P$. betle reduced biofilm formation in Avian pathogenic E. coli}


In order to investigate the activity of $P$. betle extract in the biofilm formation of APEC, the biofilm forming ability of the clinical isolates was evaluated. It was found that 3 isolates $(30 \%)$ including $\mathrm{CH} 6, \mathrm{CH}$, and $\mathrm{CH} 10$ were strong biofilm former (Table 3). The rest of the isolates produced weak biofilm formation. Hence, all the strong biofilm forming and 2 weak biofilm forming isolates were used as representative APEC to test the effects of the extract on the biofilm formation.

The activity of $P$. betle extract as inhibitors against the biofilm formation of APEC was determined using the crystal violet assay. The results demonstrated that $P$. bet/e extract at $1 / 8 \times \mathrm{MIC}, 1 / 4 \times \mathrm{MIC}$, and $1 / 2 \times \mathrm{MIC}$ significantly inhibited the bacterial biofilm formation of the clinical APEC isolates (Fig. 3B) $(P<0.05)$ without growth inhibition (Fig. $3 \mathrm{~A}$ ). In $1 / 2 \times \mathrm{MIC}$ of the extract, $55 \%$ of the biofilm inhibition was detected in APEC CH09, a strong biofilm producer. It was observed that the extract reduced the biofilm formation in the reference strain. However, the growth of the reference strain was significantly inhibited by the extract in $1 / 8 \times \mathrm{MIC}, 1 / 4$ and $1 / 2 \times \mathrm{MIC}$.

\subsection{Activity of $P$. betle on established biofilm of Avian pathogenic E. coli}

The activity of the ethanolic extract of $P$. betle leaves on the established biofilm of APEC was assessed by the MTT assay. As shown in Fig. 4, a significant reduction in the viability of young (2-day-old-biofilm) and mature (5-day-old-biofilm) biofilm-grown cells was observed after the treatment with the extract at $8 \times$ MIC when compared with the control $(P<0.05)$. In $32 \times$ MIC of $P$. betle extract, a $94 \%$ of the inhibition of viable cells embedded in the young established biofilm was detected in APEC CH09, a strong biofilm former (Fig. 4A). In addition, the $88 \%$ reduction in the viability of the isolate in the mature biofilm was detected following the treatment with the P. betle extract at 32×MIC, compared to the control (Fig. 4B).

\subsection{Inhibition of adhesion of Avian pathogenic E. coli}

The present study showed that $P$. betle reduced biofilm formation and eliminated the established biofilm of APEC. It is recognized that adhesion is the first step of biofilm formation. Hence, the activity of $P$. betle extract on adhesion of the pathogen to glass surfaces was investigated using SEM. The study was performed on representative bacteria named $\mathrm{CH} 09$, a strong biofilm producer and the reference strain. In the control groups, the bacteria, including the clinical isolate (Fig. 5A-5C) and the reference strain (Fig. 5J$5 \mathrm{~L}$ ) could regularly bind to the surface. The reduction in the bacterial adhesion to surfaces was observed when APEC were treated with sub-MICs of $P$. betle extract when compared with the control in $24 \mathrm{~h}$ (Fig. $5 D-5 I, 5 M-5 R)$.

\section{Discussion}

Avian pathogenic $E$. coli is a crucial pathogen that causes economic losses in poultry production across the globe. Furthermore, the pathogen has been considered zoonotic and serve as an external source for human extraintestinal infections. According to its strong virulence factor, including biofilms, the eradication of the pathogen by the host's immune system and antibiotic is failed. Furthermore, the 
treatment of bacterial infections is becoming difficult due to the increased antibiotic resistance of bacteria (Duan et al. 2020; Saha et al. 2020). In the present study, we focused on natural products that have antibacterial and anti-virulence activities as a therapeutic strategy for an efficient method for the control of APEC.

The results exhibited that the ethanolic extract of $P$. betle leaves had strong antibacterial activity against APEC, as revealed by both disc diffusion assays, followed by MIC and MBC determination, as well as Time kill kinetic study. The antibacterial activity of $P$. betle extract against those pathogens acquired in hospitals, including methicillin-resistant Staphylococcus aureus, ES $\beta$ L Klebsiella pneumoniae, ES $\beta \mathrm{L}$ Pseudomonas aeruginosa, and ES $\beta$ L E. coli have been reported (Valle et al. 2015). The values of the inhibition zone, MIC, and MBC of $P$. betle extract against APEC were in the same range as those of the previous reports (Valle et al. 2015). The leaf extract of $P$. betle has formerly been reported as an effective antibacterial agent. According to the results of $\mathrm{MIC}$ and $\mathrm{MBC}$ values, the $\mathrm{MBC} / \mathrm{MIC}$ ratio was less than 2 times that was considered a bactericidal agent (Nayaka et al. 2021). However, the bacteriostatic effect of the extract of $P$. betle has been documented (Taukoorah et al. 2016). Nevertheless, the present study revealed bactericidal effects of the ethanolic extract of $P$. betle against Avian pathogenic E. coli. Hence, the present study supports strong antibacterial activity of $P$. betle extract exhibiting low value of the MIC and $\mathrm{MBC}$ obtained from the results.

Interestingly, leaves of $P$. betle contain various phytochemical constituents, such as phenol, flavonoid, and tannin (Taukoorah et al. 2016) that contribute to its therapeutic potential. The main bioactive compounds in the leaf extracts of the plant species and their essential oil have been reported to consist of eugenol, phytol, 4-chromanol, hydroxychavicol, carvacrol, chavicol, chavibetol, and allylpyrocatechols 1 (Nayaka et al. 2021). Eugenol, a pure compound present in the plant, had pronounced antibacterial activity against $E$. coli with very low MIC values (Jeyakumar et al. 2021). It has been suggested that eugenol altered membrane permeability and disrupted the cells of $E$. coli, resulting in leakage of intracellular contents (Jeyakumar et al. 2021). Similarly, the disruption and breakdown of the APEC cells was detected when the cells were challenged with $P$. betle extract. It was noted that the bacterial cells treated with the extract demonstrated longer cells without septum when compared to the control. It has been reported that hydroxychavicol, a key ingredient in P. betle, induces bacterial cell death by DNA damage, ROS generation, and inhibition of the cell division (Singh et al. 2018). Furthermore, hydroxychavicol suppressed the expression of SulA, a protein under the control of SOS response (Singh et al. 2018), resulting in an inhibition of the cell division by inhibiting the formation of the FtsZ ring in response to genotoxic stress (Mukherjee et al. 1998). It has been documented that FtsZ mutant $E$. coli exhibited long cell shape without FtsZ ring formation. Therefore, the inhibition of FtsZ may be one of the possible effects of $P$. betle extract against the bacteria.

It was accepted that bacterial biofilms play a crucial role in the pathogenesis of the infection. In addition, the mechanism enables pathogens to tolerate higher concentrations of antibiotics, leading to chronic infections and the emergence of antibiotic-resistant strains (Gu et al. 2019; Hall et al. 2017; Khairy et al. 2020). The present study demonstrated that $P$. betle extract acted as an inhibitor of biofilm formation of 
the APEC. The mode of action of phytochemicals in inhibiting biofilms may involve in the inhibition of quorum sensing system and killing viable cells embedded in the biofilm (Reen et al. 2018). It understood that biofilm formation is regulated by the quorum sensing system, a cell-to-cell communication process (Wu et al. 2021). The ethanol extract of $P$. betle leaves inhibited the quorum sensing in Pseudomonas aeruginosa, resulting in an inhibition of virulence factors, including biofilms (Datta et al. 2016). In addition, eugenol, a key ingredient in P. betle, reduced biofilms in E. coli 0157: $\mathrm{H} 7$ by suppressing important genes that are required for the formation of the biofilm and the attachment and effacement phenotype (Kim et al. 2016).

Adhesion is the first step to progress in the formation of the biofilm. The present study demonstrated that $P$. betle extract reduced the adhesion of the APEC cells to the surfaces observed by SEM. Similarly, the anti-adhesion activity of $P$. betle extract against Streptocoocus mitis on saliva-coated glass surfaces has been reported (Razak et al. 2003). In addition, eugenol, a bioactive compound in $P$. betle leaves, reduced the production of fimbria in E. coli $0157: \mathrm{H} 7$, resulting in inhibition of the adhesion and biofilms (Kim et al. 2016). Our results may indicate that $P$. betle extract reduced the adhesion of APEC cells to the surface resulting in the inhibition of the biofilms. The further investigation, isolation of pure compounds from $P$. bet/e extract should be investigated. In addition, antibacterial mechanisms of the extract and the pure compounds against the pathogens should be studied. The further study should be performed in vivo to provide insight on the mechanism of $P$. betle extract against the APEC in chickens.

\section{Conclusion}

The present study reveals a bactericidal activity of $P$. betle extract against the APEC cells. The disruption and breakdown of the bacterial cells were detected when the cells were challenged with the extract. It was noted that the bacterial cells treated with the extract demonstrated longer cells without a septum when compared to the control. The extract inhibited the biofilm formation and eradicated the biofilm established in the APEC. In addition, the reduction of bacterial adhesion to surfaces were observed when APEC cells were treated with sub-MICs of $P$. betle extract when compared to the control. The results suggested potential medicinal benefits of $P$. betle extract for the treatment of the infection caused by Avian pathogenic E. coli.

\section{Declarations}

\section{Acknowledgements}

This work was funded by Research Institute for Health Sciences, Walailak University (Grant number; WUIRG-64-023). We would like to thank Research Center of Excellence in Innovation of Essential Oil and One Health Research Center, Walailak University, Thailand. Finally, we would like to thank the Project CICECOFCT, UIDB/50011/2020 and UIDP/50011/2020.

\section{Declaration of interest statement}


The authors declare no conflict of interest.

\section{Author contribution statement}

WM, SS, and VN conceived and designed the experiments. WM, PK, JC, NM and CR performed the experiments. PK, TT and WM analyzed and interpreted the data. TT, VN, and MLP contributed reagents, materials, analysis tools or data. WM, PK, MLP, and TT wrote the paper.

\section{Data availability statement}

The data that support the findings of this study are available from the corresponding author upon reasonable request.

\section{References}

1. Ali A, Kolenda R, Khan MM et al (2020) Novel avian pathogenic Escherichia coli genes responsible for adhesion to chicken and human cell lines. Appl Environ Microbiol 86(20): e0106820. https://doi.org/10.1128/AEM.01068-20

2. Cunha MPV, Saidenberg AB, Moreno AM et al (2017) Pandemic extra-intestinal pathogenic Escherichia coli (EXPEC) clonal group 06-B2-ST73 as a cause of avian colibacillosis in Brazil. PLoS One 12(6):e0178970. https://doi.org/10.1371/journal.pone.0178970

3. Datta S, Jana D, Maity TR et al (2016) Piper bet/e leaf extract affects the quorum sensing and hence virulence of Pseudomonas aeruginosa PA01. 3 Biotech 6(1):18. https://doi.org/10. 1007/s13205015-0348-8

4. Duan $Y$, Gao H, Zheng $L$ et al (2020) Antibiotic resistance and virulence of extraintestinal pathogenic Escherichia coli (ExPEC) vary according to molecular types. Front Microbiol 11:598305. https://doi.org/10.3389/fmicb.2020.598305

5. Gajewska J, Chajęcka-Wierzchowska W (2020) Biofilm formation ability and presence of adhesion genes among coagulase-negative and coagulase-positive staphylococci isolates from raw cow's milk. Pathogens 9(8):654. https://doi.org/10.3390/pathogens9080654

6. Gomes TA, Elias WP, Scaletsky IC et al (2016) Diarrheagenic Escherichia coli. Braz J Microbiol 47:330. https://doi.org/10.1016/j.bjm.2016.10.015

7. Gu H, Lee SW, Carnicelli J et al (2019) Antibiotic susceptibility of Escherichia coli cells during earlystage biofilm formation. J Bacteriol 201(18):e00034-19. https://doi.org/10.1128/JB. 00034-19

8. Hall CW, Mah TF (2017) Molecular mechanisms of biofilm-based antibiotic resistance and tolerance in pathogenic bacteria. FEMS Microbiol Rev 41(3):276-301. https://doi.org/10. 1093/femsre/fux010

9. Jaber $\mathrm{H}$, Oubihi A, Ouryemchi I et al (2021) Chemical composition and antibacterial activities of eight plant essential oils from Morocco against Escherichia colistrains isolated from different Turkey organs. Biochem Res Int 2021: 6685800. https://doi.org/10.1155/2021/ 6685800 
10. Jeyakumar GE, Lawrence R (2021) Mechanisms of bactericidal action of eugenol against Escherichia coli. J Herb Med 26:100406. https://doi.org/10.1016/j.hermed.2020.100406

11. Jørgensen SL, Stegger M, Kudirkiene E et al (2019) Diversity and population overlap between avian and human Escherichia coli belonging to sequence Type 95. mSphere 4(1): e00333-

18. https://doi.org/10.1128/mSphere.00333-18

12. Kathayat D, Lokesh D, Ranjit S, Rajashekara G (2021) Avian Pathogenic Escherichia coli (APEC): An overview of virulence and pathogenesis factors, zoonotic potential, and control strategies. Pathogens 10(4): 467. https://doi.org/10.3390/pathogens10040467

13. Khairy RMM, Fathy ZA, Mahrous DM et al (2020) Prevalence, phylogeny, and antimicrobial resistance of Escherichia coli pathotypes isolated from children less than 5 years old with community acquireddiarrhea in Upper Egypt. BMC Infect Dis 20(1):908. https://doi.org/ 10.1186/s12879-020-05664-6

14. Kim Y-G, Lee J-H, Gwon G et al (2016) Essential oils and eugenols inhibit biofilm formation and the virulence of Escherichia coli0157: H7. Sci Rep 6(1): 36377. https://doi.org/10.1038/sr ep36377

15. Lagha R, Ben Abdallah F, Al-Sarhan BO, Al-Sodany Y (2019) Antibacterial and biofilm inhibitory activity of medicinal plant essential oils against Escherichia coli isolated from UTI patients. Molecules 24(6):1161. https://doi.org/10.3390/molecules24061161

16. Mare AD, Ciurea CN, Man A et al (2021) Enteropathogenic Escherichia coli-a summary of the literature. Gastroenterol Insights 12(1):28-40. https://doi.org/10.3390/gastroent12010004

17. Meena PR, Yadav P, Hemlata H et al (2021) Poultry-origin extraintestinal Escherichia coli strains carrying the traits associated with urinary tract infection, sepsis, meningitis and avian colibacillosis in India. J Appl Microbiol 130(6):2087-2101. https://doi.org/10.1111/jam. 14905

18. Mitsuwan W, Sangkanu S, Romyasamit C et al (2020) Curcuma longa rhizome extract and Curcumin reduce the adhesion of Acanthamoeba triangularis trophozoites and cysts in polystyrene plastic surface and contact lens. Int J Parasitol Drugs Drug Resist 14:218-

229. https://doi.org/10.1016/j.ijpddr.2020.11.001

19. Mitsuwan W, Wintachai P, Voravuthikunchai SP (2020) Rhodomyrtus tomentosa leaf extract and rhodomyrtone combat Streptococcus pneumoniae biofilm and inhibit invasiveness to human lung epithelial and enhance pneumococcal phagocytosis by macrophage. Curr. Microbiol 77(11):35463554. https://doi.org/10.1007/s00284-020-02164-3

20. Mukherjee A, Cao C, Lutkenhaus J (1998) Inhibition of FtsZ polymerization by SulA, an inhibitor of septation in Escherichia coli. Proc Natl Acad Sci USA 95(6):2885-2890. https://doi.org/ 10.1073/pnas.95.6.2885

21. Nayaka NMDMW, Sasadara MMV, Sanjaya DA et al (2021) Piper betle(L): Recent review of antibacterial and antifungal properties, safety profiles, and commercial applications. Molecules 26(8):2321. https://doi.org/10.3390/molecules26082321

22. Pecková R, Doležal K, Sak B et al (2018) Effect of Piper betle on Giardia intestinalis infection in vivo. Exp Parasitol 184:39-45. https://doi.org/10.1016/j.exppara.2017.11.005 
23. Pereira WA, Pereira CDS, Assunção RG et al (2021) New insights into the antimicrobial action of cinnamaldehyde towards Escherichia coli and its effects on intestinal colonization of mice. Biomolecules 11(2):302. https://doi.org/10.3390/biom11020302

24. Razak FA, Abd Rahim ZH (20030 The anti-adherence effect of Piper betle and Psidium guajava extracts on the adhesion of early settlers in dental plaque to saliva-coated glass surfaces. $\mathrm{J}$ Oral Sci 45(4):201-206. https://doi.org/10.2334/josnusd.45.201

25. Reen FJ, Gutiérrez-Barranquero JA, Parages ML, Gara FO (2018) Coumarin: a novel player in microbial quorum sensing and biofilm formation inhibition. Appl Microbiol Biotechnol 102(5):20632073. https://doi.org/10.1007/s00253-018-8787-x

26. Rodrigues RS, Lima N, Taborda RLM et al (2019) Antibiotic resistance and biofilm formation in children with Enteropathogenic Escherichia coli (EPEC) in Brazilian Amazon. J Infect Dev Ctries 13(8):698-705. https://doi.org/10.3855/jidc.10674

27. Saha O, Hoque MN, Islam OK et al (2020) Multidrug-resistant avian pathogenic Escherichia coli strains and association of their virulence genes in Bangladesh.

Microorganisms 8(8):1135. https://doi.org/10.3390/microorganisms8081135

28. Salehi B, Zakaria ZA, Gyawali R et al (2019) Piper species: a comprehensive review on their phytochemistry, biological activities and applications. Molecules 24(7):1364. https://doi. org/10.3390/molecules 24071364

29. Sharma G, Sharma S, Sharma P et al (2016) Escherichia coli biofilm: development and therapeutic strategies. J Appl Microbiol 121(2):309-319. https://doi.org/10.1111/jam.13078

30. Singh D, Narayanamoorthy S, Gamre S et al (2018) Hydroxychavicol, a key ingredient of Piper bet/e induces bacterial cell death by DNA damage and inhibition of cell division. Free Radic Biol Med 120:62-71. https://doi.org/10.1016/j.freeradbiomed.2018.03.021

31. Stromberg ZR, Johnson JR, Fairbrother JM et al (2017) Evaluation of Escherichia coli isolates from healthy chickens to determine their potential risk to poultry and human health. PLoS One 12(7):e0180599. https://doi.org/10.1371/journal.pone.0180599

32. Tamfu AN, Ceylan O, Fru GC et al (2020) Antibiofilm, antiquorum sensing and antioxidant activity of secondary metabolites from seeds of Annona senegalensis, Persoon. Microb Pathog 144:104191. https://doi.org/10.1016/j.micpath.2020.104191

33. Taukoorah U, Lall N, Mahomoodally F (2016) Piper betle L.(betel quid) shows bacteriostatic, additive, and synergistic antimicrobial action when combined with conventional antibiotics. S Afr J Bot 105:133-140. https://doi.org/10.1016/j.sajb.2016.01.006

34. Thomrongsuwannakij T, Blackall PJ, Djordjevic SP et al (2020) A comparison of virulence genes, antimicrobial resistance profiles and genetic diversity of avian pathogenic Escherichia coli (APEC) isolates from broilers and broiler breeders in Thailand and Australia. Avian Pathol 49(5):457466. https://doi.org/10.1080/03079457.2020.1764493

35. Valle Jr DL, Andrade JI, Puzon JJM et al (2015) Antibacterial activities of ethanol extracts of Philippine medicinal plants against multidrug-resistant bacteria. Asian Pac J Trop Biomed 5(7):532- 
540. https://doi.org/10.1016/j.apjtb.2015.04.005

36. Wu L, Luo Y (2021) Bacterial quorum-sensing systems and their role in intestinal bacteria-Host crosstalk. Front Microbiol 12:611413. https://doi.org/10.3389/fmicb.2021.611413

37. Zhuge X, Zhou Z, Jiang M et al (2021) Chicken-source Escherichia coli within phylogroup $F$ shares virulence genotypes and is closely related to extraintestinal pathogenic $E$. coli causing human infections. Transbound Emerg Dis 68(2):880-895. https://doi.org/10.1111/ tbed.13755

\section{Tables}

Table 1. Antibacterial activity of the Piper bet/e leaf extract on Avian pathogenic E. coli isolated from chicken by disc diffusion assay 


\begin{tabular}{|c|c|c|c|}
\hline \multirow[t]{2}{*}{ Isolates } & \multirow{2}{*}{$\begin{array}{l}\text { Inhibition zone } \\
\text { (mm) }\end{array}$} & \multicolumn{2}{|c|}{ Antibiotic susceptibility } \\
\hline & & Ampicillin & Gentamicin \\
\hline $\mathrm{CH} 01$ & $21.00 \pm 1.00$ & $\mathrm{R}$ & $\mathrm{S}$ \\
\hline $\mathrm{CH} 02$ & $20.67 \pm 0.58$ & $\mathrm{R}$ & $\mathrm{S}$ \\
\hline $\mathrm{CH} 03$ & $19.33 \pm 1.15$ & $\mathrm{R}$ & $\mathrm{R}$ \\
\hline $\mathrm{CH} 04$ & $19.00 \pm 1.00$ & $\mathrm{R}$ & $\mathrm{S}$ \\
\hline $\mathrm{CH} 05$ & $20.00 \pm 1.00$ & $\mathrm{R}$ & $\mathrm{R}$ \\
\hline CH06 & $21.33 \pm 0.58$ & $\mathrm{R}$ & $\mathrm{S}$ \\
\hline $\mathrm{CH} 07$ & $18.67 \pm 1.53$ & $\mathrm{R}$ & $\mathrm{S}$ \\
\hline $\mathrm{CH} 08$ & $19.33 \pm 0.58$ & $\mathrm{R}$ & $\mathrm{S}$ \\
\hline CH09 & $20.00 \pm 1.00$ & $\mathrm{R}$ & $\mathrm{S}$ \\
\hline $\mathrm{CH} 10$ & $21.33 \pm 0.58$ & $\mathrm{R}$ & $\mathrm{S}$ \\
\hline E. coli ATCC25922 & $20.00 \pm 0.00$ & $\mathrm{~S}$ & $\mathrm{~S}$ \\
\hline
\end{tabular}

Table 2. Minimal inhibitory concentration (MIC) and minimal bactericidal concentration (MBC) of Piper betle leaf extract on Avian pathogenic $E$. coli isolated from chicken 


\begin{tabular}{|c|c|c|c|c|}
\hline \multirow[t]{3}{*}{ Isolates } & \multicolumn{4}{|c|}{ Antibacterial activity $(\mathrm{mg} / \mathrm{ml})$} \\
\hline & \multicolumn{2}{|c|}{ Piper betle extract } & \multicolumn{2}{|c|}{ Ceftriaxone } \\
\hline & MIC & $\mathrm{MBC}$ & MIC & $\mathrm{MBC}$ \\
\hline $\mathrm{CH} 1$ & 0.5 & 1.0 & 0.000125 & 0.00025 \\
\hline $\mathrm{CH} 2$ & 1.0 & 1.0 & 0.0005 & 0.0005 \\
\hline $\mathrm{CH} 3$ & 1.0 & 1.0 & 0.00025 & 0.00025 \\
\hline $\mathrm{CH} 4$ & 1.0 & 1.0 & 0.0005 & 0.0005 \\
\hline $\mathrm{CH} 5$ & 1.0 & 1.0 & 0.00025 & 0.00025 \\
\hline $\mathrm{CH} 6$ & 0.5 & 1.0 & 0.00025 & 0.0005 \\
\hline $\mathrm{CH} 7$ & 0.5 & 1.0 & 0.0005 & 0.0005 \\
\hline $\mathrm{CH} 8$ & 0.5 & 1.0 & 0.0005 & 0.0005 \\
\hline $\mathrm{CH} 9$ & 0.5 & 1.0 & 0.00025 & 0.00025 \\
\hline $\mathrm{CH} 10$ & 0.5 & 1.0 & 0.00025 & 0.00025 \\
\hline E. coli ATCC25922 & 0.5 & 1.0 & 0.00025 & 0.00025 \\
\hline
\end{tabular}

Table 3. Biofilm forming ability of clinical isolates of Avian pathogenic E. coli

\begin{tabular}{|lll|}
\hline Biofilm forming ability & Number of strains & Percent of the isolates \\
\hline Non & 0 & 0 \\
Weak & 7 & 70 \\
Moderate & 0 & 0 \\
Strong & 3 & 30 \\
\hline
\end{tabular}


Figures

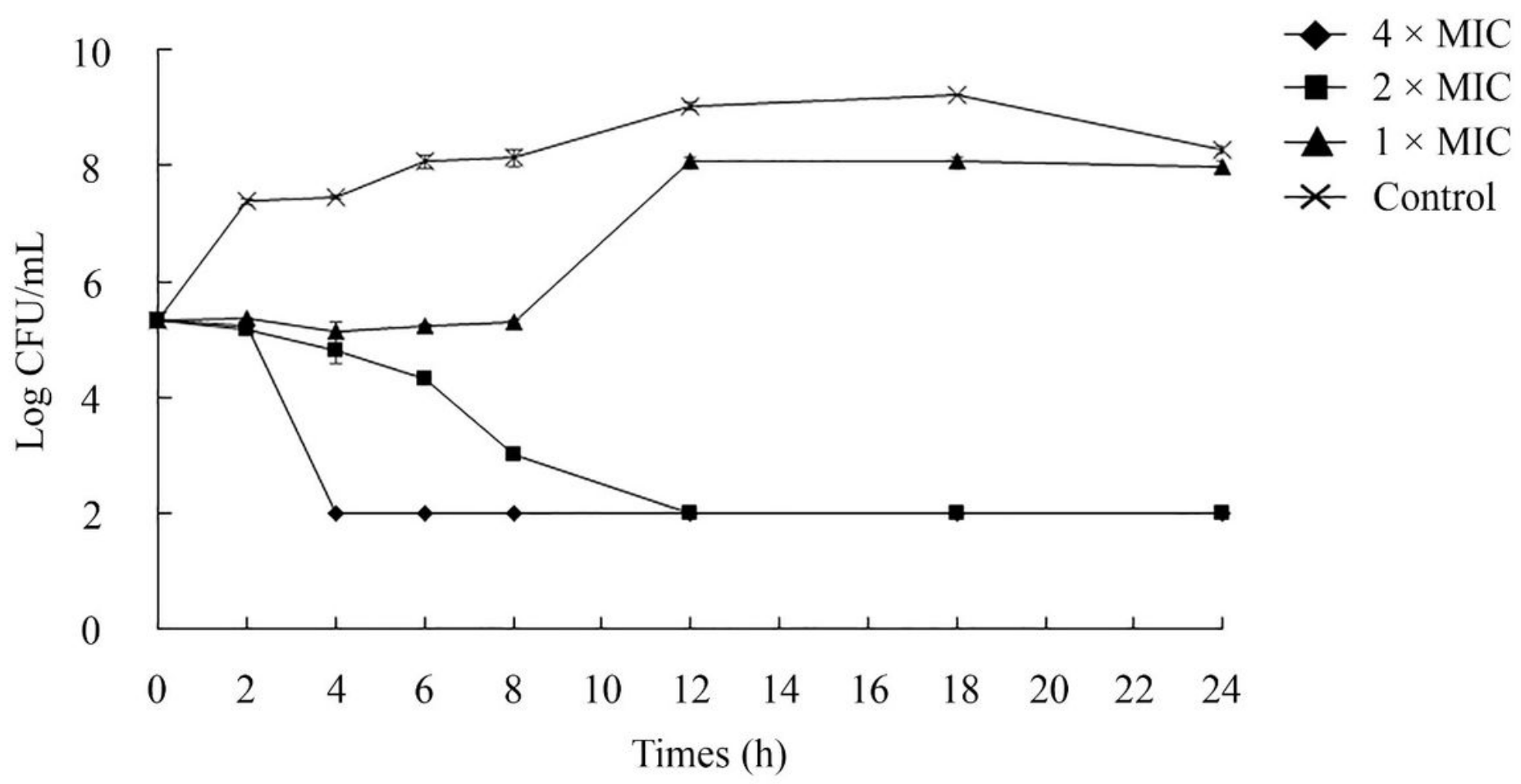

\section{Figure 1}

Time-kill curves of Avian pathogenic E. coli $\mathrm{CH} 09$ after treatment with P. betle extract. The bacterium was treated with the extract at $4 \times \mathrm{MIC}, 2 \times \mathrm{MIC}, 1 \times \mathrm{MIC}$. One percent DMSO was used as a negative control. Each symbol indicates the mean $\pm S D$. 
Control
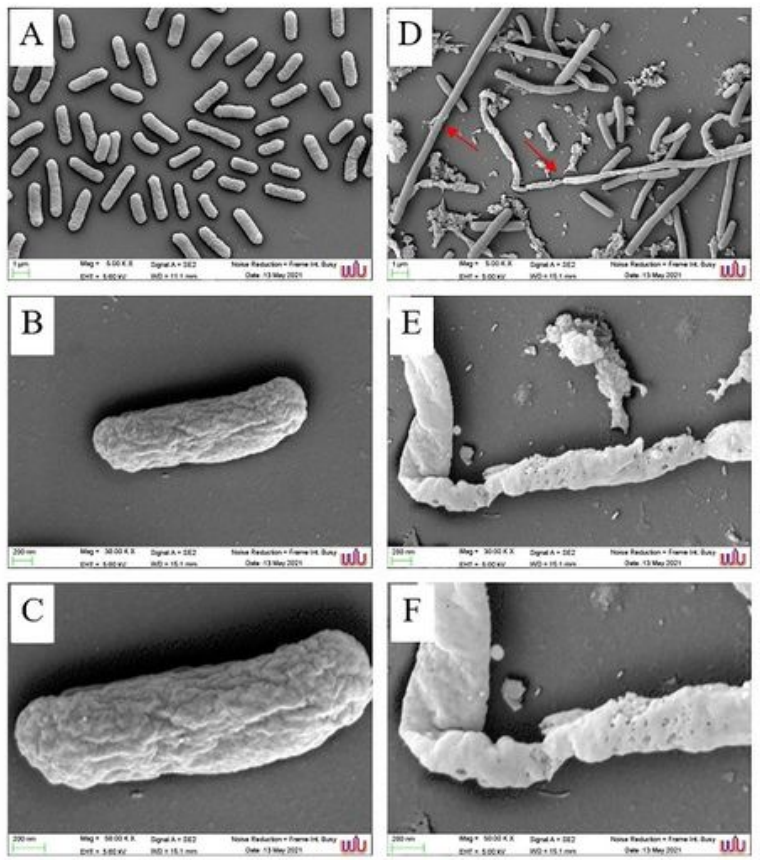

Control
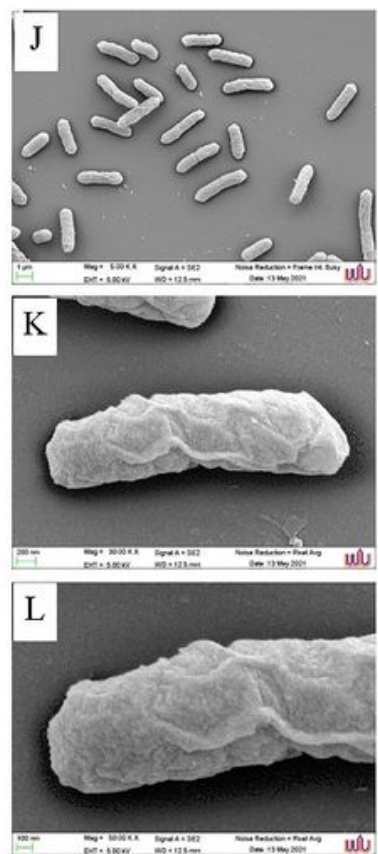

E. coli ATCC 25922

$2 \times \mathrm{MIC}$
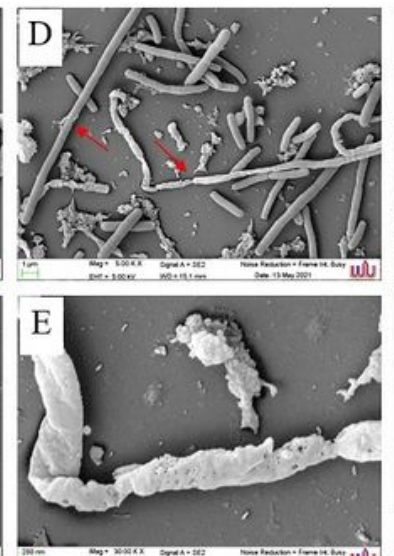

$2 \times \mathrm{MIC}$
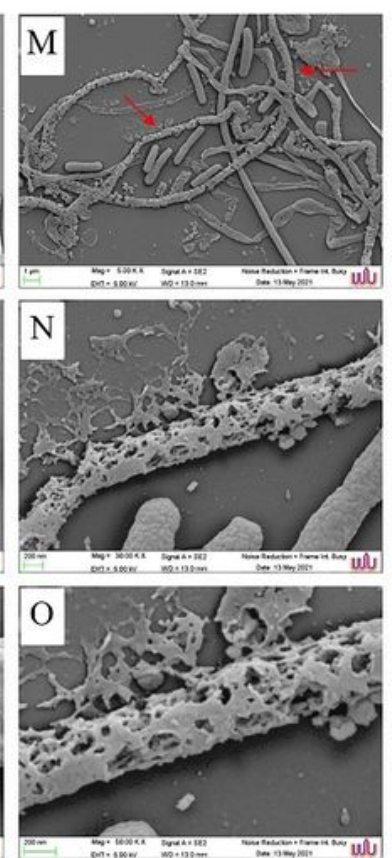

$4 \times \mathrm{MIC}$
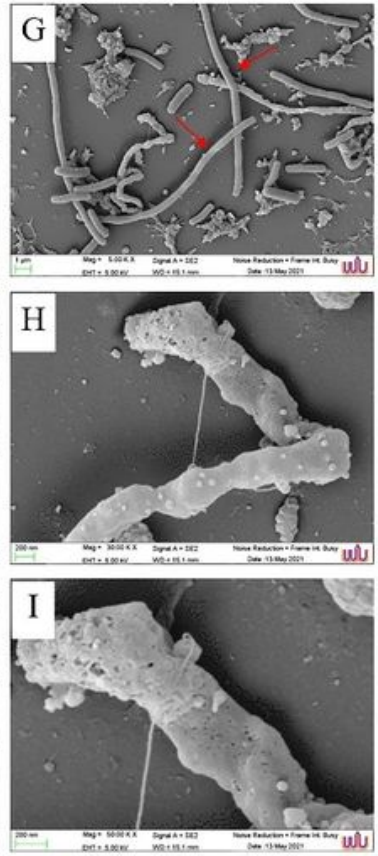

$4 \times$ MIC
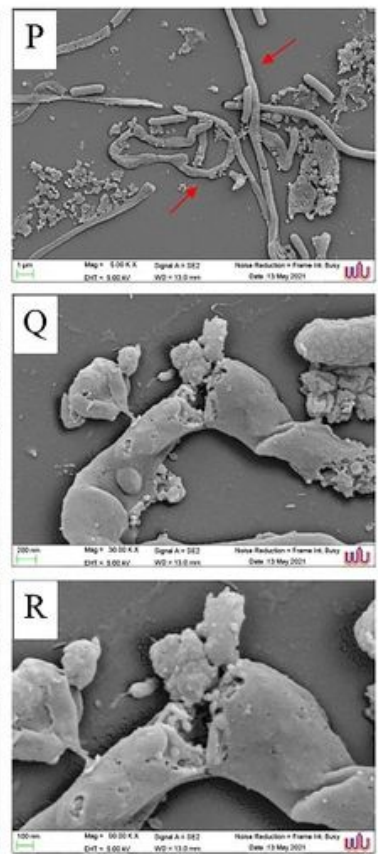

\section{Figure 2}

Morphylogy of Avian pathogenic E. coli CH09 (A-I) and ATCC25922 (J-R) after treatment with P. betle extract observed by SEM. The bacterial cells were treated with the extracts at $2 \times \mathrm{MIC}$ and $4 \times \mathrm{MIC}$. One percent DMSO was used as a negative control. Magnifications were revealed as: $A, D, G, J, M, P=5,000 X$; $B, E, H, K, N, Q=30,000 X ; C, F, I, L, O, R=50,000 X$. 

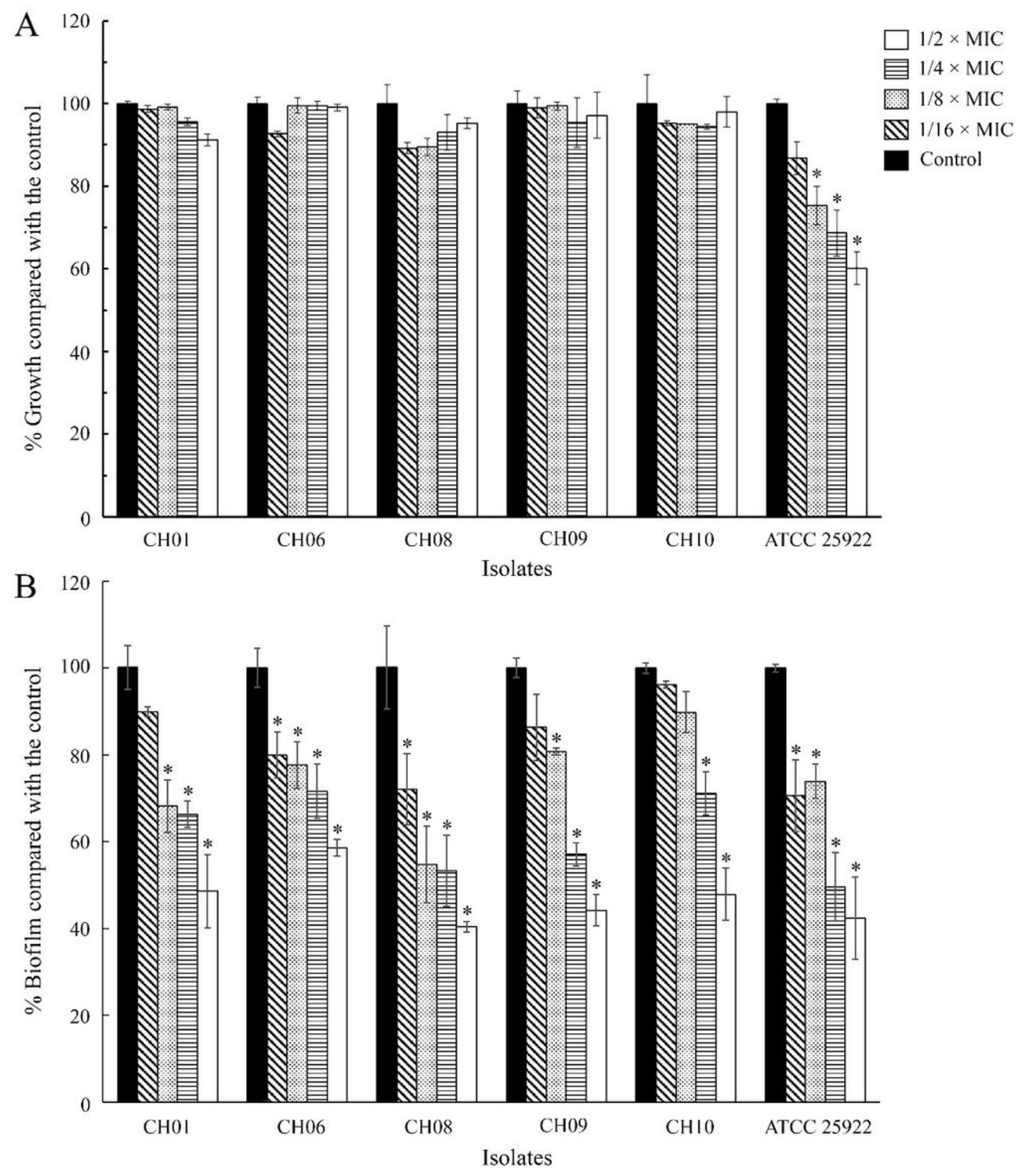

Figure 3

Effects of P. betle extract on the growth (A) and biofilm formation (B) of Avian pathogenic E. coli. The pathogens were grown in the medium supplemented with P. betle extract at sub-MICs. One percent DMSO was used as a negative control. The relative percentage of biofilm formation was defined as: (mean A570 of treated well/mean A570 of control well) $\times 100$. The data was presented as mean \pm SD (* significant difference; $P<0.05)$. 

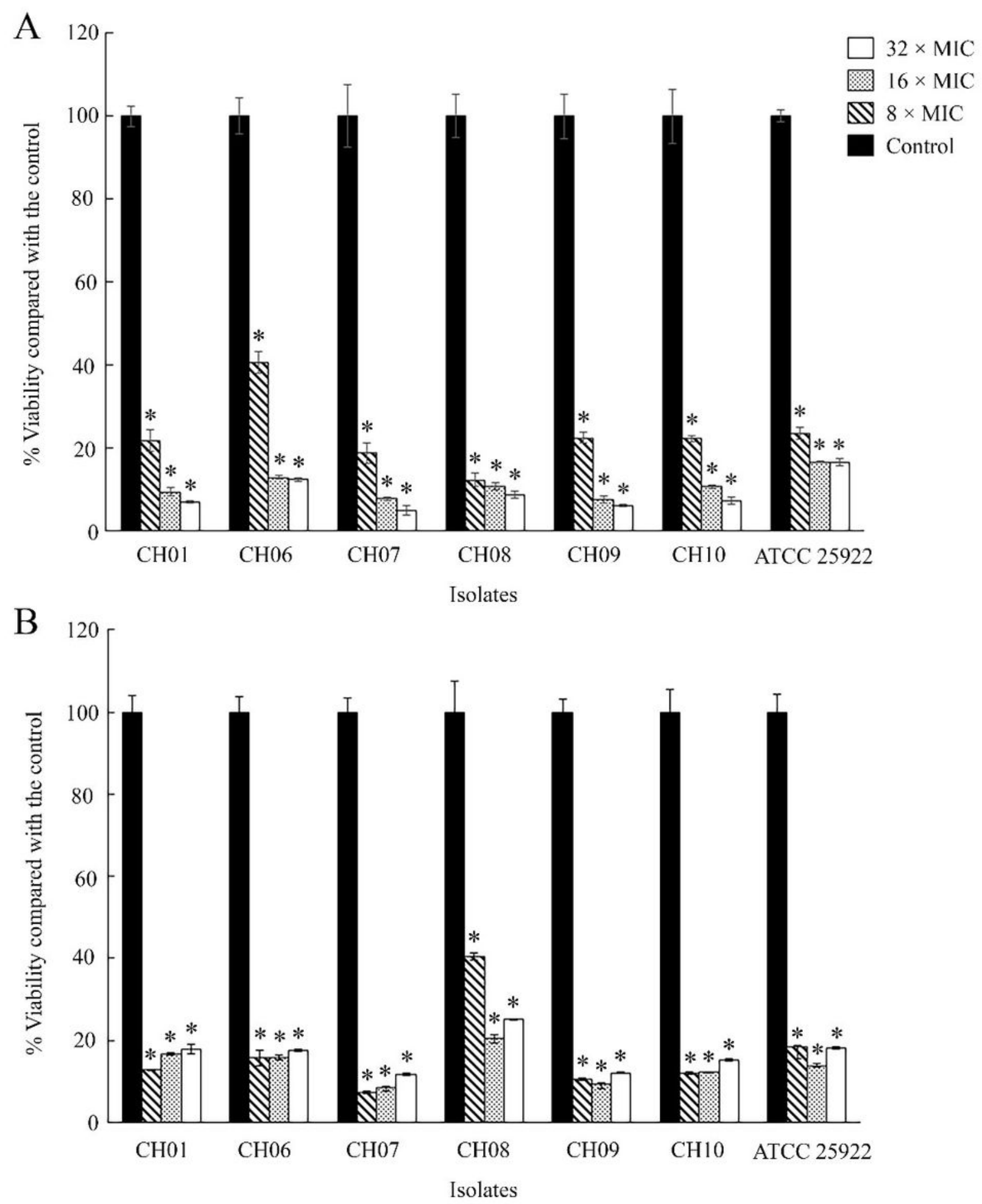

Figure 4

Effects of P. betle extract on established biofilm of Avian pathogenic E. coli. The bacteria were grown in the medium supplemented to produce young, 2 days (A) and mature, 5 days (B) biofilms. The biofilm was treated with $\mathrm{P}$. betle extract at different concentrations. One percent DMSO was used as a negative control. The relative percentage of biofilm viability was defined as: (mean A570 of treated well/mean A570 of control well) $\times 100$. The data was presented as mean \pm SD (* significant difference; $P<0.05$ ). 
Control
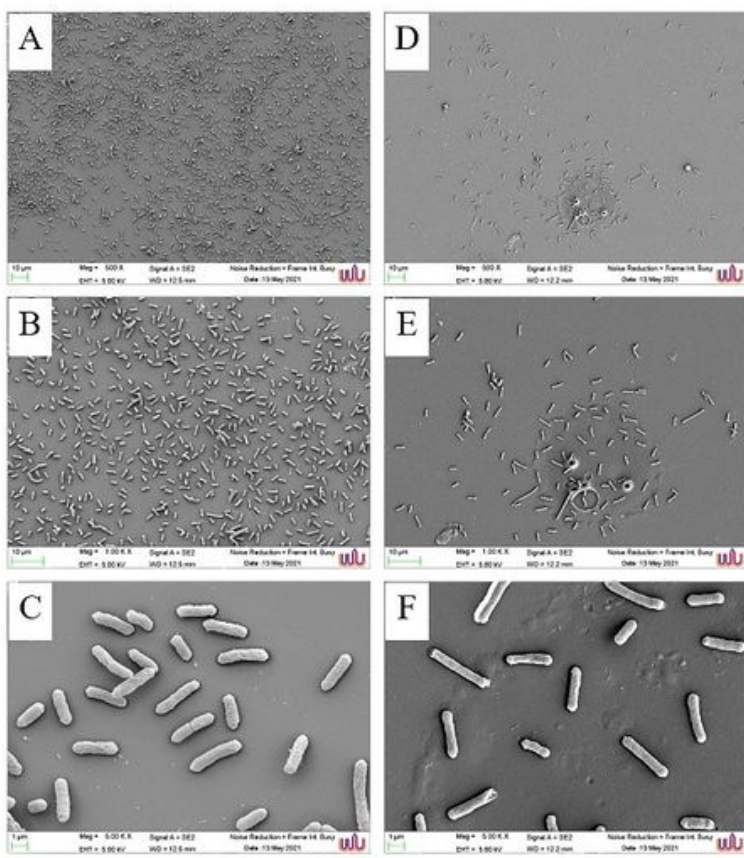

\section{E. coli $\mathrm{ATCC} 25922$}

Control
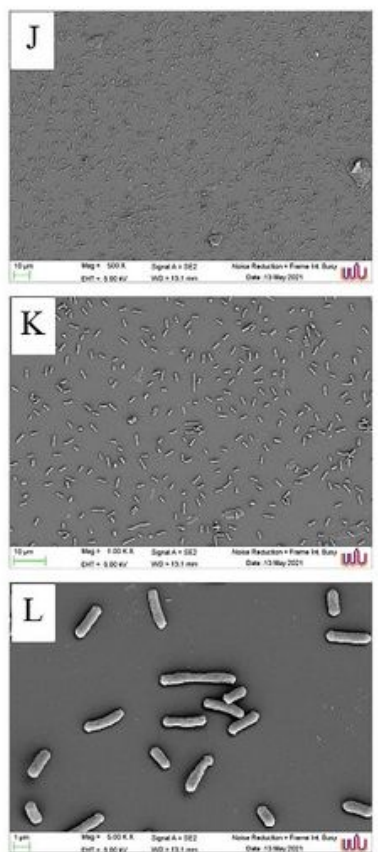

$1 / 4 \times$ MIC

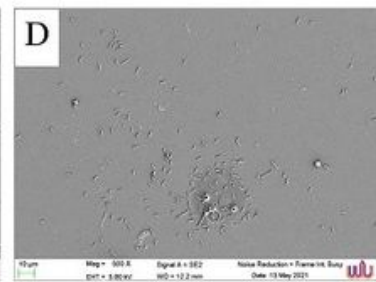

$1 / 4 \times \mathrm{MIC}$
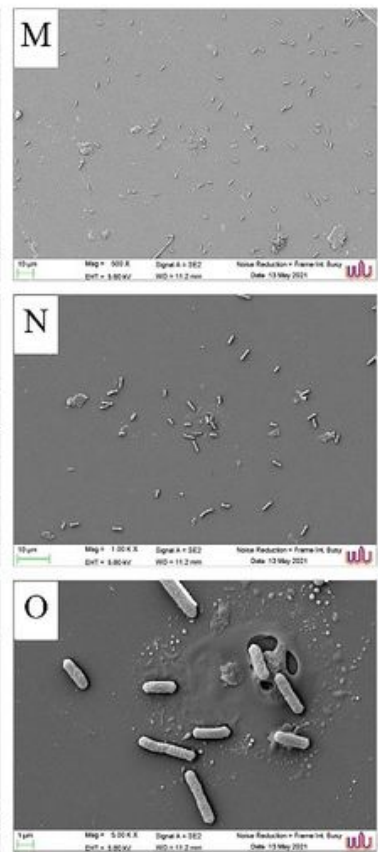
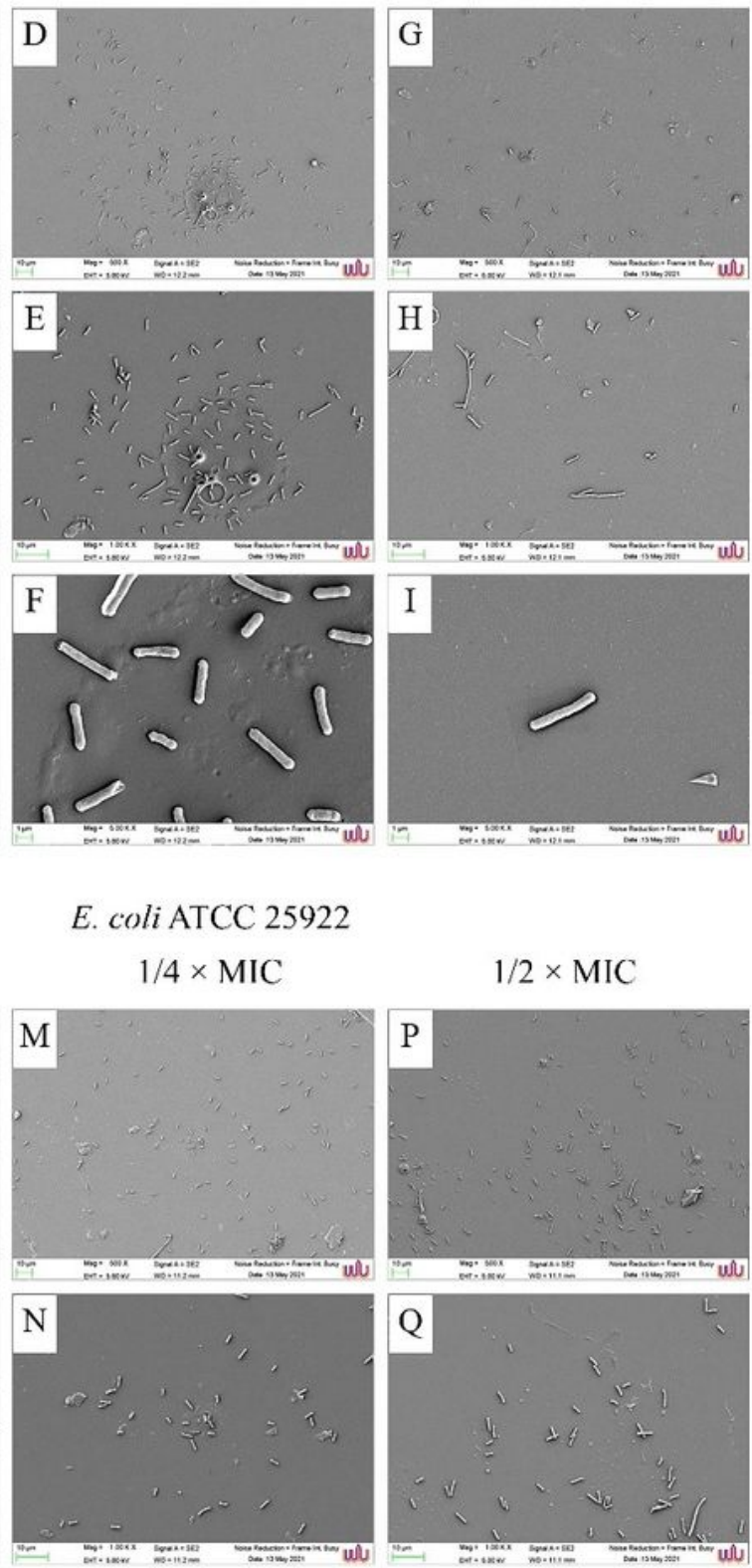

$1 / 2 \times \mathrm{MIC}$
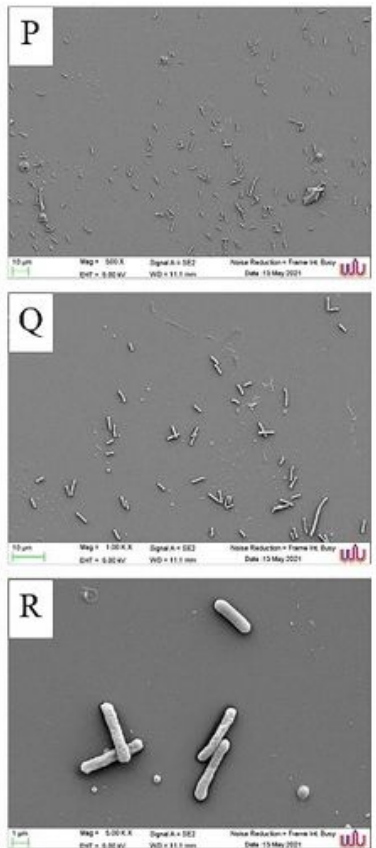

\section{Figure 5}

Activity of P. betle extract on the adhesion of Avian pathogenic E. coli CH09 (A-I) and ATCC25922 (J-R) observed by SEM. The bacterial cells were cultured in the medium supplemented with the extracts at $1 / 4 \times$ MIC and 1/2×MIC. One percent DMSO was used as a negative control. Magnifications were revealed as: $A, D, G, J, M, P=500 X ; B, E, H, K, N, Q=1,000 X ; C, F, I, L, O, R=5,000 X$. 